\title{
CES
}

COOPERATIVISMO E ECONOMÍA SOCIAL

Núm. 40 (2017-2018), páxs. 305-311

ISSN: 1130-2682

\section{ANOTAÇÃO AO AC. TRE DE 9.2.2017 \\ (PROC. 34/12.1T2STC-A.E1). \\ SOBRE O WISHFUL THINKING E A LEI}

\section{ANNOTATION TO THE JUDGMENT OF THE ÉVORA COURT OF APPEAL JUDGEMENT 9.2.2017 (PROC. 34/12.1T2STC-A.E1). WISHFUL THINKING AND THE LAW}

Alexandre de Soveral Martins ${ }^{1}$

1 Doutor em Ciências Jurídico-Empresarias (Universidade de Coimbra)/Professor Auxiliar da Faculdade de Direito da Universidade de Coimbra (soveralm@fd.uc.pt ; Faculdade de Direito, Pátio da Universidade, Coimbra). 



\section{INTRODUÇÃO. Os PROBLEMAS}

To Acórdão do Tribunal da Relação de Évora de 9.2.2017, que teve por Relator o Desembargador Paulo Amaral, foi defendido que seria de aplicar a uma associação sem fins lucrativos o art 260. ${ }^{\circ}$ do CSC. Daí decorreria que aquela pessoa coletiva ficaria vinculada pela atuação de um só titular do órgão dirigente.

Consideramos, porém, que ambas as soluções não correspondem à adequada aplicação do regime jurídico em vigor quando se trate de associação com personalidade jurídica (art. 158. ${ }^{\circ}, 1$, do CCiv.). Vejamos porquê.

\section{O SENTIDO DO ART. 260. ${ }^{\circ}$, I, DO CSC}

Comecemos pelo que é, na nossa opinião, a correta interpretação do art. $260 .^{\circ}$ do $\mathrm{CSC}^{1}$. Interessa-nos agora o que nos diz o seu n. ${ }^{\circ} 1$ : «Os atos praticados pelos gerentes, em nome da sociedade e dentro dos poderes que a lei lhes confere, vinculam-na para com terceiros, não obstante as limitações constantes do contrato social ou resultantes de deliberações dos sócios».

A solução que vemos a constar do preceito reproduzido resulta da transposição da Primeira Diretiva sobre direito das sociedades. Este texto, no entanto, era apenas aplicável a sociedades por quotas, anónimas e em comandita por ações.

A invocação daquela Diretiva deve ser aqui feita porque só desse modo se compreende âmbito de aplicação do art. $2600^{\circ}$, 1, do CSC. E é porque estamos perante a transposição daquela Diretiva que não temos dúvidas em afirmar que o mencionado preceito tem em vista as limitações aos poderes de representação dos gerentes que digam respeito à extensão dos mesmos e não às limitações que somente tenham em vista o modo de exercício daqueles poderes.

É a própria letra do preceito, aliás, que o revela. O art. 260. ${ }^{\circ}$ 1, começa por fazer menção aos «atos praticados pelos gerentes» que vinculam a sociedade para com terceiros «não obstante as limitações constantes do contrato social ou resultantes de deliberações dos sócios». As limitações em causa são, por isso, as relativas aos atos que os gerentes podem praticar: os atos que são mencionados no início daquele n. ${ }^{\circ} 1$.

Note-se ainda que o art. $99^{\circ}, 3$, da Primeira Diretiva dava atenção às limitações relativas ao modo de exercício dos poderes de representação. E essas limitações

\footnotetext{
1 Para uma análise mais desenvolvida e com muitas referências bibliográficas (também discordantes) v. o nosso comentário aos arts. $260 .^{\circ}$ e $261 .^{\circ}$ do CSC, em J. M. Coutinho de Abreu (coord.), Código das Sociedades Comerciais em comentário, IV, 2. ${ }^{a}$ ed., Almedina, Coimbra, 2017.
} 
poderiam ser consideradas oponíveis a terceiros pela legislação interna dos Estados-Membros.

Isto era assim porque a preocupação da Diretiva europeia estava centrada nas dificuldades que as incertezas surgidas na interpretação das cláusulas do contrato de sociedade ou do teor das deliberações dos sócios que dissessem respeito à natureza dos atos poderiam causar às trocas entre agentes económicos de diferentes Estados-Membros: garantia, coisa, bem imóvel, Sicherheit, Verpfändung, são termos que podem não ser facilmente compreensíveis em ordenamentos jurídicos europeus diferentes. A preocupação não era tão grande relativamente à capacidade dos terceiros em saberem contar: em francês, dois são dois; em alemão, três são três.

Quanto às limitações relativas ao modo de exercício dos poderes de representação dos gerentes, a solução deve ser procurada no art. $261 .^{\circ}$ do CSC, cujo n. ${ }^{\circ} 1$ tem a seguinte redação: «Quando haja vários gerentes e salvo cláusula do contrato de sociedade que disponha de modo diverso, os respetivos poderes são exercidos conjuntamente, considerando-se válidas as deliberações que reúnam os votos da maioria e a sociedade vinculada pelos negócios jurídicos concluídos pela maioria dos gerentes ou por ela ratificados». O CSC português usou, assim, a possibilidade que era aberta pelo art. 9. ${ }^{\circ}, 3$, da Primeira Diretiva: contém uma norma que regula o exercício dos poderes de representação pelos gerentes (em regra, a sociedade por quotas fica vinculada pelos negócios concluídos pela maioria); essa norma pode ser afastada por cláusula do contrato de sociedade que estabeleça um regime diferente; esse regime constante do contrato de sociedade será oponível a terceiros. No que diz respeito a esta última afirmação impõem-se alguns desenvolvimentos.

Com efeito, aquela oponibilidade a terceiros resulta da própria letra do art. $260{ }^{\circ}, 1$ : se não há cláusula que disponha diversamente, a sociedade fica vinculada pela maioria dos gerentes; se não intervém a maioria, a sociedade não fica vinculada; se há cláusula que disponha diversamente (exigindo, por exemplo, a intervenção de um número superior ao da maioria), a sociedade fica vinculada com a intervenção do número de gerentes exigido por essa cláusula; se não intervém o número de gerentes exigido pela cláusula do contrato de sociedade, esta não fica vinculada. E não fica vinculada perante terceiros, obviamente. Além disso, se o contrato de sociedade estiver registado e publicado também se aplica o art. $14 .^{\circ}$, 2, do CRC e $168 .^{\circ}, 2$ e 3 , do CSC.

A tudo o que se disse deve somar-se um argumento que se extrai do teor do art. 261. ․, 2, do CSC: os gerentes-delegados só vinculam a sociedade «se a delegação lhes atribuir expressamente tal poder». Trata-se de um regime que não faria sentido se qualquer gerente, sozinho, vinculasse sempre a sociedade: afinal de contas, os gerentes-delegados também são gerentes. 
O que dizemos não significa que sejamos defensores da solução legalmente consagrada. Pelo contrário. Na nossa opinião, a melhor solução seria a de estabelecer a vinculação da sociedade por quotas através da intervenção de qualquer um dos gerentes. Mas não foi essa a ponderação dos interesses em presença que feita pelo legislador nacional de 1986. Entre os interesses da sociedade e dos sócios, de um lado, e os interesses de terceiros, do outro, a lei fez opções. E são opções que não são descabidas: afinal de contas, o terceiro não está dispensado de conhecer o teor do contrato de sociedade devidamente registado e publicado nem está dispensado de saber contar.

\section{A ANALOGIA LEGIS SERVE PARA PREENCHER LACUNAS}

Impõe-se analisar agora a questão de saber se fará sentido recorrer ao regime das sociedades por quotas para o aplicar por analogia a uma associação com personalidade jurídica.

Julgamos que a resposta tem que ser negativa. Com efeito, o próprio CCiv. já contém normas que são aplicáveis à atuação em nome daquelas associações, o que afasta a necessidade de recurso à analogia ${ }^{2}$. Desde logo, o art. 167. ', 1, que dispõe que o ato de constituição das mesmas especificará, entre outras coisas, a forma do seu funcionamento. Acresce que o art. $163 .^{\circ}, 1$, que se integra no regime geral das pessoas coletivas, também estabelece que a «representação da pessoa coletiva, em juízo e fora dele, cabe a quem os estatutos determinarem ou, na falta de disposição estatutária, à administração ou a quem por ela for designado». Curiosamente, o n. ${ }^{\text {o }}$ 2 do mesmo art. $163 .^{\circ}$ acrescenta que a «designação de representantes por parte da administração só é oponível a terceiros quando se prove que estes a conheciam». Veja-se bem: esta limitação quanto à oponibilidade de designação de representantes apenas diz respeito a representantes designados pela administração.

Quanto ao que consta dos estatutos, também não se pode olvidar o teor do art. $168 .^{\circ}$ do CCiv.: o n. ${ }^{\circ} 2$ ocupa-se da publicação da constituição e estatutos da associação e o n. ${ }^{\circ} 3$ revela que, uma vez efetuada a publicação, o ato de constituição e os estatutos produzem efeitos em relação a terceiros ${ }^{3}$. E isso só pode significar que também serão oponíveis as cláusulas que deles constem quanto à forma de funcionamento da pessoa coletiva e, em particular, quanto à representação da pessoa coletiva (em juízo e fora dele).

No caso das associações sem personalidade jurídica, o art. 195. ${ }^{\circ}, 2$, acrescenta algo mais que é relevante para os problemas que estamos a analisar: aquela nor-

2 Com outra opinião, invocando um princípio da confiança e da aparência, Pedro Pais de Vasconcelos, Teoria Geral do Direito Civil, 6. ${ }^{a}$ ed., Coimbra Editora, Coimbra, 2010, p. 178 e s..

3 Defendendo que antes da publicação o ato de constituição e os estatutos não serão oponíveis a terceiros de boa fé (os terceiros que desconhecem sem culpa), António Menezes Cordeiro, Tratado de Direito Civil Português, I, t. III, Almedina, Coimbra, 2004, p. 657. 
ma dispõe que as «limitações impostas aos poderes normais dos administradores só são oponíveis a terceiro quando este as conhecia ou devia conhecer». As limitações em causa são, julgamos nós, as que resultam das regras estabelecidas pelos associados (art. 195. $\left.{ }^{\circ}, 1\right)$. Nomeadamente, as limitações quanto ao modo de exercício dos poderes de representação pelos membros do órgão de administração ${ }^{4}$. Mas isto mostra também que nas associações com personalidade jurídica a solução é outra.

As associações sem fins lucrativos têm o seu regime marcado por isso mesmo: pelo seu fim não lucrativo. E por isso o regime é bem diferente do que encontramos previsto no CSC, por exemplo, para as sociedades por quotas ou anónimas ${ }^{5}$. Desde logo, o cunho personalístico é ali muito mais forte do que numa sociedade anónima ou, até, numa sociedade por quotas. Basta ver o que encontramos dito no art. $180{ }^{\circ}$ do CCiv.: «Salvo disposição estatutária em contrário, a qualidade de associado não é transmissível, quer por ato entre vivos, quer por sucessão; o associado não pode incumbir outrem de exercer os seus direitos pessoais».

Além disso, nas associações de fim desinteressado ou altruístico a maior proteção dos interesses da associação e dos associados justifica-se porque à «comunidade importa que tais interesses sejam satisfeitos, mesmo por iniciativa particular, porque, faltando esta, seria ela chamada e obrigada à prossecução dos interesses mencionados, empenhando agora os seus recursos próprios $»^{6}$. Quanto às associações de fim interessado ou egoístico, se é certo que os interesses que visam satisfazer são diferentes, «a comunidade está interessada em que aqueles interesses egoísticos ou próprios dos associados sejam prosseguidos, visto haver uma certa coincidência entre as aspirações particulares e os interesses gerais da comunidade, uma vez que esta é beneficiada, pelo menos reflexamente» ${ }^{7}$.

$\mathrm{O}$ que dissemos até agora justifica que, na ponderação dos interesses da associação, dos associados e dos terceiros, a balança esteja calibrada de forma diferente relativamente à que pondera os interesses das sociedades comerciais, dos

\footnotetext{
${ }^{4}$ Mesmo no que diz respeito às associações sem personalidade jurídica há que ter em conta que se deve «partir do princípio de que quem estabelece relações jurídicas com estas se deve certificar da existência de poderes representativos de quem atua, suscitando, se necessário, e para tanto, a exibição de documentos que comprovem essa qualidade e, por associação, a existência dos correlativos poderes»: João Zenha Martins, Das associações sem personalidade jurídica, Almedina, Coimbra, 2016, p. 195 e s..

5 Destacando também que é «outra a posição do Código Civil, ao disciplinar as associações. Isto é coerente com a natureza das associações, que têm na base um grupo de pessoas», Oliveira Ascensão, Direito Civil - Teoria Geral, vol. I, Coimbra Editora, Coimbra, 1997, p. 291.

6 heinrich Ewald Hörster, A Parte Geral do Código Civil Português, Almedina, Coimbra, 1992, p. 372.

7 heinrich Ewald Hörster, A Parte Geral do Código Civil Português, cit., p. 599. As citações extensas são também uma forma de prestar homenagem aos ensinamentos do Professor Heinrich Ewald Hörster.
} 
respetivos sócios e de terceiros. Essa balança, evidentemente, é a lei. E essa lei também assegura confiança. Desde logo, a terceiros que saibam contar.

\section{E SE HOUVESSE LACUNA?}

Mesmo que se considere que existe lacuna no regime aplicável diretamente às associações com personalidade jurídica quanto às questões abordadas no Acórdão anotado, a verdade é que o caminho a seguir para o seu preenchimento não deve ser o de recorrer ao art. $2600^{\circ}$ do CSC. Com efeito, as associações têm um cunho fortemente personalístico. Justificar-se-ia, por isso, o recurso ao art. $996 .^{\circ}$ do CCiv. (a sociedade é representada pelos seus administradores «nos termos do contrato [...]») e ao art. 192. $.^{\circ}, 3$, do CSC. Este último preceito permite à sociedade a «impugnação», em regra, de atos praticados pelos gerentes com falta de poderes que resulte, designadamente, da violação de limitações resultantes do contrato de sociedade. 